\title{
HACIA UNA HISTORIOGRAFÍA LITERARIA COSTARRICENSE DEL PERIODO COLONIAL
}

Alexánder Sánchez Mora

\section{(c) $(1)(9)$}

Doi: https://doi.org/10.15517/rfl.v46iExt..43504

URL: https://revistas.ucr.ac.cr/index.php/filyling/index 



\title{
HACIA UNA HISTORIOGRAFÍA LITERARIA COSTARRICENSE DEL PERIODO COLONIAL
}

\author{
TOWARDS A COSTA RICAN LITERARY \\ HISTORIOGRAPHY OF THE COLONIAL PERIOD
}

Alexánder Sánchez Mora

\begin{abstract}
RESUMEN
La historiografía literaria costarricense se ha construido a partir de la convención de que la literatura surge en el país durante de la segunda mitad del siglo XIX. Este artículo propone un recorrido por las causas históricas de tal prejuicio y por las opiniones descalificadoras de los historiadores literarios costarricenses. Se propone la necesaria fundación de una corriente historiográfica que, desde la multidisciplinariedad y a partir de la exploración de géneros discursivos poco conocidos, redefina el objeto de estudio de la literatura colonial. Por último, se postulan, a manera de hoja de ruta, las tareas necesarias para su constitución.

Palabras clave: historiografía literaria; literatura centroamericana; literatura colonial; literatura barroca; reino de Guatemala.
\end{abstract}

\begin{abstract}
Costa Rican literary historiography has been built from the convention that literature arises in the country from the second half of the 19th century. This article proposes a journey through the historical causes of such prejudice and through the disqualifying opinions of Costa Rican literary historians. It proposes the necessary foundation of a historiographical current that, from multidisciplinarity and from the exploration of little-known discursive genres, redefines the object of study of colonial literature. Finally, the necessary tasks for its constitution are postulated as a road map.

Keywords: literary historiography; Central American literature; colonial literature; baroque literature; Kingdom of Guatemala.
\end{abstract}

\section{Las vicisitudes de una provincia periférica}

Los estudios literarios coloniales en Costa Rica se encuentran apenas en ciernes. A despecho de algunos encomiables esfuerzos, la crítica literaria académica ha concentrado su interés en la literatura latinoamericana, incluida la centroamericana, de los siglos XX y XXI y en la costarricense que comienza a publicarse a partir de la década de 1880. Las causas de este desinterés por la producción literaria de los más de tres siglos del periodo colonial son

Dr. Alexánder Sánchez Mora. Profesor Catedrático de la Escuela de Filología, Lingüística y Literatura. Universidad de Costa Rica. San José, Costa Rica.

Correo electrónico: alexander.sanchez@ucr.ac.cr 
diversas, pero parten todas de la configuración histórica inicial de la provincia de Costa Rica como región marginal dentro del contexto global de los dominios españoles en América y del particular de la audiencia de Guatemala.

En términos generales, la dominación española del continente americano se consolidó con prontitud en aquellas regiones que prometían fáciles ganancias merced a la atractiva presencia de yacimientos de metales preciosos y de altas concentraciones de población nativa. Las capitales virreinales de México y Lima se convirtieron en pocos años en los ricos centros económicos y administrativos de extensas regiones articuladas básicamente en torno a la extracción argentífera ${ }^{1}$. La situación resultó muy diferente en el territorio centroamericano que, desde las décadas iniciales de la conquista y con la limitada excepción de Honduras, mostró carecer de oro y plata. La pobreza mineral resultó compensada, desde la perspectiva de los invasores europeos, por la presencia de importantes núcleos de población en el altiplano guatemalteco y en las tierras bajas de la extensa franja costera del Pacífico. Estas dos circunstancias combinadas marcarán el carácter periférico de la economía centroamericana, siempre urgida por encontrar un producto que le permitiera vincularse con los canales del comercio continental.

Si bien la conquista de las principales zonas de población en el altiplano guatemalteco y en las tierras bajas del Pacífico fue lenta y dificultosa, la situación se había estabilizado hacia 1530, pero ello no significa que la totalidad del istmo hubiese sido "pacificada". El valle central de Costa Rica, asentamiento de Cartago, capital provincial fundada en 1564, fue apenas controlado en la segunda mitad de la centuria por las tropas de Juan Vázquez de Coronado y Perafán de Ribera (Molina y Palmer, 1997, pp. 24-25). La situación fue peor aún para los españoles en las tierras cálidas y húmedas del Caribe, el mayor desafío para la empresa conquistadora, pues su presencia en ellas fue más bien endeble y nunca llegó a ser definitiva. El clima, las enfermedades tropicales, la vegetación agreste, los patrones de asentamiento dispersos, la inexistencia de una línea de avituallamiento, la tenaz resistencia indígena y las propias disputas entre los conquistadores impidieron que las múltiples fundaciones españolas subsistieran más allá de unos pocos años. En la Talamanca costarricense, los intentos de penetración se sucedieron sin éxito a lo largo de los siglos XVII y XVIII y debieron enfrentar sublevaciones indígenas como la de los "ateos, viceitas, térrebes y cabécaras" en 1610, que destruyó la ciudad de Santiago de Talamanca y significó la expulsión de los españoles de la región (Fernández Guardia, 1975, p. 173)², y el gran movimiento de 1709 dirigido por Pablo Presbere.

El cultivo del cacao se extendió en el valle de Matina, en el Caribe costarricense, hacia la década de 1660 y gozó de dos breves periodos de auge durante el siglo XVIII (1727-1747 y 1770-1780), asociados con la exportación legal a Portobelo y Cartagena e ilegal a Jamaica

1 Sobre este tema, pueden consultarse los trabajos de Lavallé (2019), Serrera Contreras (2013), Miño Grijalva (2001), Bakewell (1976), entre otros.

2 Con el topónimo Talamanca se designa la región sureste de la actual provincia de Limón en su límite con Panamá. En lo administrativo, se ubica en la Región Huetar Atlántica, cantón de Talamanca, que comprende el valle y la cordillera del mismo nombre (Borge y Castillo, 1997, pp. 3-12). El topónimo proviene de la ciudad que en esa zona se fundó, el 10 de octubre de 1605, Diego de Sojo y Peñaranda con el nombre de Santiago de Talamanca, en honor de la Villa de Talamanca, provincia de Madrid, de la que era nativo (Guevara y Chacón, 1992, p. 65; Montero Barrantes, 2003, p. 48). Sobre la rebelión indígena y la destrucción de Santiago de Talamanca, ver Ruz (1991, p. 73), Solórzano (1992, p. 194) y Quirós (1996, p. 168). 
y Curazao (Molina y Palmer, 1997, pp. 29-31; MacLeod, 1973, pp. 330-340; Rosés Alvarado, 1982, pp. 247-277). El puerto de Matina se convirtió en el eje de un activo contrabando con los ingleses y zambos mosquitos, gracias al cual los habitantes de Cartago se suplían de textiles, utensilios metálicos, armas y papel (Cardoso y Pérez Brignoli, 1977, p. 83; Brenes Castillo, 1978; Solórzano Fonseca, 1994, pp. 71-119; Fonseca Corrales, Alvarenga Venutolo y Solórzano Fonseca, 2003, pp. 280-282; Hunt, 2013, pp. 5-6). Aunque la actividad estimuló la economía provincial y le facilitó una moneda en especie, para finales de siglo la competencia del cacao venezolano y guayaquileño, sumada a los ataques piráticos, los impuestos, y la carencia de una adecuada red vial y portuaria, la habían condenado a la decadencia (Molina y Palmer, 1997, p. 30; Chacón Hidalgo, 2008, pp. 137-148 y 2014, pp. 82-84) ${ }^{3}$. Con todo y el impacto dinamizador del cacao sobre la vida de esta provincia periférica, Madrigal Muñoz, a partir de un análisis prosopográfico y de relaciones micro sociales, ha demostrado que los productores de cacao fueron en realidad un grupo subordinado dentro de la élite provincial, que si bien gozaba de cierto prestigio y riqueza, no detentó el poder político (2011, pp. 106-132 y 2014, pp. 103-112).

Los esfuerzos integradores de las autoridades coloniales serían continuados, tras la declaración de la independencia, por los nacientes estados nacionales con la fugaz anexión al Imperio Mexicano de Agustín de Iturbide (1822-1823) y luego con el intento de consolidar la República Federal de Centroamérica (1824-1839) ${ }^{4}$. El proyecto federal, minado desde sus bases por la desconfianza hacia las pretensiones hegemónicas guatemaltecas, las ambiciones de los caudillos locales, las desavenencias económicas e ideológicas al interior de las élites, la inexperiencia administrativa y el intervencionismo inglés, condujo pronto al caos de las guerras civiles entre liberales y conservadores y a la total quiebra del sistema institucional. El experimento se saldó, entre 1838 y 1841, con la constitución de cinco estados nacionales y la disolución de la República 5 .

La inexistencia de un ciclo productivo duradero que permitiera la inclusión de las diversas provincias en un entramado económico único impidió su cohesión a largo plazo y, por el contrario, propició la formación de alianzas regionales más modestas como, por ejemplo, la del ciclo añilero salvadoreño (Fernández Molina, 2003) o el de la crianza de mulas en Costa

3 A pesar de la existencia de una ceca en Guatemala, en la que se acuñaba desde 1733, “[...] amplios espacios de la Audiencia habían vivido una importante escasez de moneda acuñada que convivía con otras formas no oficiales de medios de cambio, como había sucedido en otras zonas del imperio español" (Acosta Rodríguez, 2012, pp. 307-308).

4 Para una imagen de las relaciones entre Centroamérica y el México de Iturbide, consúltense Peralta (1968), Wortman (1976), Luján Muñoz (1977), Toussaint, Rodriguez de Ita y Vásquez de Olivera (2001) y Vázquez Olivera (2004 y 2010). Inmaculada Rodríguez Moya (2003 y 2006, pp. 287-315) ha realizado un sugestivo estudio sobre el culto a Iturbide a partir de su iconografía. Tras la caída de Iturbide, el general Vicente Filísola, comandante de las fuerzas mexicanas de ocupación en Guatemala, convocó a una Asamblea Nacional Constituyente en la que participaron representantes de todas las antiguas provincias y que declaró, el $1^{\circ}$ de julio de 1823 , la independencia respecto de España, México y cualquier otra potencia y el nacimiento de las Provincias Unidas del Centro de América, germen de la República Federal al año siguiente (Hall y Pérez Brignoli, 2003, p. 41).

5 Entre las carencias que condujeron al fracaso del experimento federal se cuentan la incapacidad de diseñar un Ejecutivo fuerte y dotado de un ejército que le permitiera ejercer control sobre las milicias y los caudillos locales, la inexistencia de un distrito federal y la ineficiencia de las estructuras hacendarias (Díaz Arias, 2013, p. 69). Sobre la historia de la República Federal, véanse Townsend Ezcurra (1973), Obregón Loría (1977), Botey (1994) y Vázquez Vicente (2011). 
Rica destinadas a Panamá y Perú (Molina Montes de Oca, 2005). Así, no es de extrañar que el triángulo Norte (Guatemala, Honduras, El Salvador) y el binomio Sur (Nicaragua, Costa Rica), muy vinculado con Panamá y aun con Perú, se perfilaran a lo largo de los siglos coloniales como asociaciones hasta cierto punto independientes e inconexas.

Esta relativa desvinculación de Costa Rica respecto de Centroamérica se vería reforzada a partir de la segunda mitad del siglo XIX, cuando el proceso de invención de la nacionalidad costarricense enfatizaría las diferencias, reales e imaginadas, entre una Costa Rica que se proclamaba pacífica, laboriosa y blanca frente a una Centroamérica, en especial Nicaragua, tachada de violenta, caótica y oscura ${ }^{6}$. En consonancia con esa tradición de insularidad, la historiografía literaria costarricense, desde su nacimiento, ha privilegiado una perspectiva totalmente nacionalista que ha soslayado la existencia de patrones de escritura compartidos a partir de vínculos regionales tales como las redes intelectuales y los canales institucionales de circulación de la cultura letrada. Consecuentemente, el periodo colonial centroamericano no ha resultado de interés y ha sido concebido como ajeno por completo a la tradición de escritura literaria costarricense, la cual habría surgido, en apariencia ex nihilo, en la pujante San José de la década de 1880.

\section{La pretendida inexistencia de una literatura colonial costarricense}

Las limitaciones materiales impuestas por una economía precaria han sido esgrimidas tradicionalmente como argumento explicativo de la inexistencia de una verdadera cultura literaria durante el periodo colonial en Costa Rica ${ }^{7}$. La crítica ha sostenido que la literatura nace en territorio costarricense apenas con el siglo XIX, específicamente en las décadas de 1880 y 1890. Un tácito acuerdo ha dicho que los 250 años de dominio español dejaron como único legado literario las coplas de Domingo Jiménez (1574), la noticia -porque el texto se perdió- de la loa escrita por el gobernador Diego de la Haya con motivo de los festejos por la proclamación de Luis I (1725), las coplas de Gordiano Paniagua (1802) ${ }^{8}$ y los entremeses representados con motivo de la jura de Fernando VII (1809) ${ }^{9}$. Como figuras destacadas se menciona a dos sacerdotes, fray Antonio de Liendo y Goicoechea y Florencio del Castillo, quienes hicieron carrera fuera de la provincia, básicamente como oradores y ensayistas ${ }^{10}$.

$6 \quad$ Sobre el proceso de invención de la nacionalidad en Costa Rica, Palmer (1992 y 1995).

7 Chacón Hidalgo (2005) ha estudiado la percepción de la pobreza en la Costa Rica de los siglos XVII y XVIII.

8 Estas coplas se conservaron como prueba documental dentro de la causa judicial que se siguió contra su autor por sus intentos de seducir a una mujer casada (Blanco Segura, 1997, pp. 157-168).

9 Ricardo Blanco Segura también menciona unos "versos incluidos en una nota relativa a la venta de la casa de Miguel Ibarra (1753)" y un himno en honor a Nuestra Señora de los Ángeles compuesto por Rafael Francisco Osejo a inicios del siglo XIX (1983, p. 297). Según Sanabria Martínez, quien transcribe el texto, el canto Ave maris stella de Osejo data de 1804 (1985, pp. 432-433).

10 La figura de Florencio del Castillo ha gozado de súbita vigencia a causa de la celebración del bicentenario de la Constitución de Cádiz. Castillo, diputado de Costa Rica ante las cortes, fungió como presidente de estas en 1813. Tras décadas de relativo olvido, recientemente se han publicado tres estudios sobre su vida y obra: El evangelio de don Florencio: palabra, pensamiento y peregrinación de don Florencio del Castillo (1778-1834) (2008) de Armando Vargas, El presbitero Florencio del Castillo (2010) y El canónigo Florencio Castillo: sus luces en un México independiente y federal (2013) de Manuel de Jesús Benavides Barquero. 
La negación sistemática de la existencia de la escritura literaria colonial se comprueba con un rápido repaso de los momentos fundacionales de la crítica y la historia literaria en Costa Rica a fines del siglo XIX y principios del XX. En ellos jugó un papel determinante la figura del abogado cubano Antonio Zambrana, quien ejerció un magisterio innegable en la conformación de los círculos intelectuales finiseculares ${ }^{11}$; su voz se convirtió en criterio de autoridad, tal y como quedó demostrado en la polémica literaria de 1894, cuando condenó el incipiente modernismo de Ricardo Fernández Guardia y alentó la reacción del realismo nacionalista liderada por Carlos Gagini (Sánchez Mora, 2003, pp. 104-105) ${ }^{12}$.

Las propuestas estéticas de Zambrana, imbuidas del idealismo croceano y del impresionismo crítico francés, se impusieron con fuerza en el medio costarricense durante varias décadas (Villalobos, 2005). Un resultado inmediato de esa influencia fue que los incipientes estudios literarios se hayan circunscrito al comentario impresionista de los textos contemporáneos y que hayan renunciado por completo a todo intento de investigación del pasado colonial. Esto es particularmente revelador si se considera que justo en ese momento -en las últimas tres décadas del siglo XIX- se producía una verdadera efervescencia que desembocaría en el nacimiento de la historiografía costarricense, primero con los trabajos de recopilación documental de Felipe Molina, León Fernández, Manuel María de Peralta y Pedro Pérez Zeledón, y luego con los textos pioneros de Joaquín Bernardo Calvo, Francisco Montero Barrantes, Ricardo Fernández Guardia y Cleto González Víquez (Sánchez Mora, 2007, p. 65)13.

Los textos de crítica literaria de las décadas siguientes, como Crítica literaria (1929) de Ricardo Rojas Vincenzi, La cultura literaria (1930) de Justo Facio y Crítica americana (1936) de Roberto Brenes Mesén, son deudores del imaginario difundido por Zambrana. La excepción en esos años es Sobre los estudios estéticos (1926) de Rafael Estrada, en donde se propone la necesidad de comprender la obra de arte literaria tanto dentro de la subjetividad del artista como a partir de sus causas históricas (Villalobos, 2005, p. 135). El impacto de la obra de Estrada fue muy limitado, puesto que él mismo no realizó estudios literarios de conformidad con tales presupuestos.

La tardía aparición de los estudios literarios con perspectiva histórica puede fijarse en 1938 con Literatura costarricense de Rogelio Sotela. Sin embargo, este acto fundacional, paradójicamente, niega desde un inicio la existencia de una tradición colonial. Sotela fija el primer impulso literario del país en el grupo de escritores que denomina "precursores" y que vivieron a fines de la colonia y en torno a los primeros decenios de la época republicana: Antonio

11 Sobre Zambrana, véase Láscaris Comneno (1964) y Vargas Araya (2006).

12 Dicha polémica es considerada como un hito en la construcción del código de lo verosímil que guiaría la escritura literaria costarricense de buena parte del siglo XX. La bibliografía sobre el tema es amplia: Castro Rawson (1966), Bonilla (1981), Chase (1975), Quesada (1986), Valdeperas (1991), Ovares, Rojas, Santander y Carballo (1993), Barrantes (1997), Rojas y Ovares (1995a), Quesada (1999), Sánchez Mora (2003). Los documentos de la polémica fueron reunidos en Segura Montero (1995).

13 El discurso histórico nace en Costa Rica, durante la segunda mitad del XIX, en el marco del proceso de consolidación del Estado y de invención de la especificidad nacional. Los problemas de límites con Colombia y, a partir de 1903, con Panamá y el proyecto liberal de elaboración de una identidad que convocara la lealtad de los diversos grupos sociales jugaron un papel determinante en la elaboración, por primera vez, de una imagen sistemática y documentada de Costa Rica como unidad independiente. Sobre el tema, Acuña Ortega (1985-1986), González Villalobos (1988), Quesada Camacho (2003) y Sánchez Mora (2007). 
de Liendo y Goicoechea (1735-1814), Florencio del Castillo (1778-1834), José María Castro Madriz (1818-1892), Jesús Jiménez (1823-1897), Manuel Argüello Mora (1834-1902) y otros. A pesar de la mención de tales "precursores", Sotela considera que la "vida literaria” de Costa Rica "en verdad no se define sino con los hombres que nacieron hacia el año 1860" (1938, p. 5).

La Historia de la literatura costarricense (1957) de Abelardo Bonilla era el recuento más completo que se había hecho del tema hasta ese momento y aún hoy es de obligada consulta por la cantidad de información que ofrece ${ }^{14}$. Desde la propia introducción, Bonilla es claro al sostener "la ausencia, en sus orígenes, de una sólida cultura colonial que nos privó de la herencia literaria española del Siglo de Oro" (1981, p. 18); unas páginas más adelante reafirma que "No existió la poderosa raíz colonial en el nacimiento de nuestra literatura" (1981, p. 21). Además de las coplas de Domingo Jiménez, a las que tacha de "mediocre composición" (1981, p. 48), solo dedica atención a los sacerdotes ilustrados Antonio de Liendo y Goicoechea y Florencio del Castillo, aunque considerados como figuras excepcionales dentro de "nuestro oscuro y pobre período colonial" (1981, p. 61).

Tras la Historia de Bonilla, aún hoy la mayoría de obras pasan por alto el periodo colonial o lo despacha con una rápida mención. Un ejemplo claro es el de Jorge Valdeperas en Para una nueva interpretación de la literatura costarricense (1979), primer análisis de corte marxista efectuado en el país, toma la segunda mitad del siglo XIX como punto de partida para su estudio. A partir de la década de 1980, la crítica se concentró en el estudio de la literatura como uno de los discursos que contribuyeron a la construcción del imaginario nacional a fines del siglo XIX. La literatura comenzó a ser considerada -dentro de la línea de Eric Hobsbawn y Benedict Anderson- en sus relaciones tensas y contradictorias con los discursos que, desde la oficialidad, articularon la invención de la nación costarricense. Buena muestra de tal inclinación se encuentra en las obras de Álvaro Quesada La formación de la narrativa nacional costarricense 1890-1910. Enfoque histórico social (1986), La voz desgarrada. La crisis del discurso oligárquico y la narrativa costarricense (1917-1919) (1988) y Uno y los otros (1999), así como en La casa paterna. Escritura y nación en Costa Rica (1993) de Flora Ovares et al. y en los dos volúmenes de En el tinglado de la eterna comedia. Teatro costarricense (1995b) de Margarita Rojas y Flora Ovares.

Las únicas dos historias literarias escritas en las últimas décadas también omiten toda referencia a la producción textual de la colonia. 100 años de literatura costarricense (1995a) de Flora Ovares y Margarita Rojas anuncia, desde su propio título, que el discurso literario se constituye en el país solo a partir de las décadas finales del siglo XIX. Por su parte, en el manual Breve historia de la literatura costarricense (2000), altamente apreciado por la crítica, Álvaro Quesada se limita a señalar que "Durante la colonia y casi todo el siglo XIX, la producción literaria en el territorio de lo que hoy es la República de Costa Rica fue poco importante" (2008, p. 15). De allí en adelante solo se ocupará de la conformación de un circuito de producción y consumo de discursos literarios a partir de las dos décadas finales del siglo XIX.

La historiografía literaria costarricense, de esta forma, se ha asentado sobre una imagen de juventud y de carencia de tradición. Ante la inexistencia de textos prehispánicos

14 Su título original es Historia y antología de la literatura costarricense (1957), pero a partir de la segunda edición la Historia y la Antología se han publicado en volúmenes separados. El estudio más detallado sobre el libro de Bonilla se encuentra en Zavala, Araya y Chacón (1995).

Doi: https://doi.org/10.15517/rfl.v46iExt..43504 / URL: https://revistas.ucr.ac.cr/index.php/filyling/index 
que permitieran hablar de una tradición literaria indígena ${ }^{15}$ y la debilidad de la ciudad letrada de los siglos XVI a XVIII, se ha repetido hasta la saciedad que existe un vacío discursivo que abarca todo el periodo colonial y que solo vendría a ser remediado por la eclosión literaria de fines del siglo XIX.

\section{Propuestas para la (re)fundación de una historiografía literaria colonial en Costa Rica}

Dado el panorama hasta aquí esbozado, podría creerse que las perspectivas para los estudios de la literatura colonial en Costa Rica son poco halagüeñas. Sin embargo, esto no es así: los años recientes han atestiguado un renovado interés por este campo y, además, por crear espacios institucionales de investigación y de intercambio académico. A partir de estas nuevas condiciones es que proponemos seis tareas necesarias para constituir, de manera estable y como proyecto colectivo, una corriente historiográfica enfocada en la literatura colonial centroamericana.

\subsection{Primera tarea. Tomar conciencia de que sí existe literatura colonial costarricense}

Si bien el volumen de la literatura colonial costarricense es muy reducido, la historia y la crítica literaria lo han limitado aún más, pues han trabajado a partir de un corpus anclado a definiciones tradicionales de los géneros literarios. Nuestra propuesta se dirige, por lo tanto, hacia la ampliación de ese corpus, no mediante el espectacular y muy teatral descubrimiento de textos perdidos durante siglos en polvosos archivos conventuales, sino mediante una fórmula más simple: la reformulación del campo literario mediante el estudio de otros textos que durante mucho tiempo fueron concebidos tan solo como fuente de información referencial, pero que pueden ser considerados como parte de la formación discursiva literaria tanto porque incorporan en su proceso de escritura recursos y temáticas propias de la ficción como porque su recepción fue similar a la de los textos reconocidos como literarios (Sánchez Mora, 2019).

En síntesis, la apertura del corpus pasa por profundizar en el estudio de diversos géneros discursivos que hasta ahora solo han sido tratados como documentos por los historiadores y no como textos literarios por la crítica literaria. Dentro de los posibles géneros hasta ahora invisibilizados se encuentran las relaciones de $\operatorname{sucesos}^{16}$, los sermones ${ }^{17}$, la hagiografía e, incluso, las relaciones de méritos y servicios.

15 Tan solo en las últimas décadas, gracias a lingüistas como Adolfo Constenla Umaña, Carla Victoria Jara y Miguel Ángel Quesada, se han publicado algunas recopilaciones de la tradición oral de bribris, cabécares y borucas: Leyendas y tradiciones borucas (1979) de Espíritu Santo Maroto, Itté. Historias bribris (1993), Narraciones borucas (1996), Poesía tradicional indigena costarricense (1996), Kó késka. El lugar del tiempo. Historias y otras tradiciones orales del pueblo bribri (1997) y Poesía bribri de lo cotidiano (2006).

16 Nieves Pena Sueiro (2005, pp. 40-47) ofrece una completa clasificación de los diversos tipos de relaciones de sucesos.

17 Christophe Belaubre (2016), desde una perspectiva histórica, ha efectuado un pertinente estudio de los sermones guatemaltecos. 


\subsection{Segunda tarea. Recuperar el oficio clásico del filólogo}

De manera paradójica, aunque la apertura del corpus colonial no se basa en el hallazgo de textos perdidos, la inclusión de nuevos géneros discursivos dentro de la denominación de literatura propicia y estimula la investigación en archivos. Muchos de esos textos han pasado desapercibidos para la historiografía tradicional, de modo que nunca han sido publicados. Por ello, es indispensable -y urgente- que los historiadores de la literatura se sumerjan en el Archivo Nacional de Costa Rica, el Archivo Histórico Arquidiocesano, el Archivo General de Centroamérica, el Archivo General de la Nación de México, el Archivo General de Indias y todos aquellos repositorios que resguarden documentos coloniales centroamericanos.

Tras la detección de los documentos se abre un nuevo desafío: su trascripción y edición crítica. En la escuela filológica costarricense, no han sido prioritarias las disciplinas que permiten esta labor: la paleografía y la edición. La adquisición de tales herramientas por parte de los estudiantes y los investigadores es un requisito sine qua non para la profesionalización del campo.

\subsection{Tercera tarea. Expandir el horizonte geográfico de nuestros estudios}

Si bien, como quedó arriba apuntado, es posible -y necesario- ampliar el corpus de la literatura colonial costarricense, este seguirá siendo, por las limitaciones propias de una sociedad provinciana, bastante pobre en comparación con el enorme y complejo acervo literario novohispano. Por ello, la historiografía literaria colonial costarricense debe aspirar a abarcar la textualidad literaria escrita en el periodo colonial, esto es desde el primer contacto de los españoles con la tierra americana hasta el momento de la independencia en 1821, en la jurisdicción completa del reino de Guatemala (las actuales repúblicas de Guatemala, El Salvador, Honduras, Nicaragua y Costa Rica, más el estado mexicano de Chiapas). Si los colonialistas costarricenses se abocan a la investigación de la literatura de toda la región, entendida como área cultural, podrán captar y evidenciar los vasos comunicantes que atraviesan el istmo, es decir, la existencia de una tradición de escritura compartida, pero también de particularidades locales que responden a procesos peculiares de adaptación de esos códigos generales hispánicos.

\subsection{Cuarta tarea. Asumir el reto de la multidisciplinariedad}

El trabajo que se anuncia deberá ser, de manera ineludible, multidisciplinario. La naturaleza misma de los textos por estudiar hace que para el investigador literario sea indispensable recurrir a los aportes de lingüistas, historiadores, archivistas, antropólogos, historiadores del arte, arquitectos, historiadores del Derecho y de la música, así como de cualquier otra disciplina que arroje luz sobre los discursos coloniales y sus circunstancias de producción, circulación y consumo.

El estudioso de la literatura colonial encuentra un apoyo inmediato y esencial en la investigación lingüística. La colaboración con los lingüistas se impone en diversos sentidos: en primer lugar, por ser la disciplina hermana, la que comparte con los estudios literarios una preocupación de base por la lengua como objeto de estudio; en un segundo término, por cuanto existe un fructífero diálogo entre los principios teóricos y metodológicos de ambos saberes; y, por último, porque lingüistas e historiadores de la literatura compartimos una misma formación de base e, incluso, idénticos espacios académicos. 
En el Instituto de Investigaciones Lingüísticas de la Universidad de Costa Rica, merece una mención especial el proyecto Constitución de un corpus histórico para el español colonial de Costa Rica, dirigido por la Dra. Gabriela Cruz Volio. Este proyecto responde a la urgente necesidad de paliar la carencia de una base documental, en formato electrónico, que permita dotar de continuidad a los estudios diacrónicos de las variedades del español en Costa Rica. Esta base documental servirá, además, como un repositorio lingüístico y cultural, útil para los estudios literarios, históricos y antropológicos, entre otros. Las investigaciones que se efectúen a partir de un corpus como este tendrán un carácter más fidedigno, preciso y verificable, en tanto podrán ser contrastadas. Por último, este corpus va más allá de la mera recopilación, pues se sustenta en la elaboración de transcripciones paleográficas, que facilitan tanto el análisis del sistema gráfico y sus valores fonéticos, como la preparación de ediciones filológicas que permiten una lectura ágil y comprensiva (Cruz Volio, 2020).

\subsection{Quinta tarea. Construir un panorama de los estudios coloniales literarios en Costa Rica, su pasado y su presente}

A pesar de que los estudios de la literatura colonial, como ha quedado demostrado, no han gozado de gran popularidad en Costa Rica, no se puede afirmar que los esfuerzos actuales partan de una tabula rasa. Cualquier intento por promover su desarrollo debe pasar por rastrear la existencia de una tradición de investigaciones sobre la discursividad colonial, por más que esta sea bastante tardía y marginal dentro de la historiografía literaria del país. A continuación, se ofrecerá un primer acercamiento, somero y de carácter más bien panorámico, a tales trabajos. Una de las tantas tareas pendientes será el efectuar un estudio crítico de este estado de la cuestión ${ }^{18}$.

La historiografía literaria del periodo colonial debe reconocer a Constantino Láscaris y Carlos Meléndez, dos figuras señeras de la intelectualidad costarricense de la segunda mitad del siglo XX, como sus pioneros. Ambos, a pesar de provenir de especialidades diversas de la literatura, se cuentan entre los primeros que mostraron interés por los discursos literarios del periodo. El filósofo Láscaris, antes de radicarse en Costa Rica, ya había escrito un estudio sobre Sor Juana Inés de la Cruz (1952) y, más adelante, dedicaría un capítulo de su Historia de las ideas en Centroamérica (1970) a la época colonial. Por su parte, el historiador Meléndez efectuó una valoración de conjunto de lo que denominó el "teatro culterano" del periodo colonial centroamericano (1984).

Durante las décadas de 1980 y 1990, se vislumbra un incipiente interés por la literatura colonial. Así, aparecerá lo que es posible que sea el primer estudio monográfico dedicado a textos literarios de la colonia costarricense: "Las cartas de Juan Vázquez de Coronado. Praxis de una conquista" (1986) de Julieta Dobles Yzaguirre. A él le seguirían los trabajos de María Elia Rodríguez H. sobre el Periquillo Sarniento (1988), de Yadira Calvo sobre dos escritoras barrocas: la española María de Zayas y Sor Juana Inés de la Cruz (1987), y de José Otilio Umaña Chaverri en torno al Diario de Cristóbal Colón (1992). Rima de Vallbona es autora de un artículo sobre los conventos coloniales como espacios de libertad para la creación artística femenina (1995), de otro en el que trata la obra de Sor Juana Inés de la Cruz y de Anne

18 En el Anexo de este artículo se ofrece una bibliografía provisional de los estudios costarricenses sobre literatura colonial. 
Bradstret desde la óptica de la represión patriarcal (2000) y de la primera edición crítica de un texto colonial hecha por un investigador costarricense: la Vida i Sucesos de la Monja Alférez (1993). Desde una perspectiva sociocrítica, Ivonne Robles Mohs publica tres estudios sobre las Cartas de relación de Hernán Cortés (1994a, 1994b y 1994c), en tanto que Sonia Marta Mora un libro en el que ahonda en El Periquillo Sarniento de Fernández de Lizardi como punto de partida de la novela hispanoamericana (1995).

En esa misma década final del siglo XX despunta la figura de Juan Durán Luzio, central dentro de los estudios coloniales en Costa Rica, tanto por la constancia de su interés como por la profundidad de su trabajo. Ha abordado temas tan diversos como la Rusticatio mexicana de Landívar (1991), las estructuras narrativas empleadas por fray Bernardino de Sahagún (2005b), el paso de Colón por Costa Rica en 1502, las cartas de relación de Juan Vásquez de Coronado, los textos de Liendo y Goicoechea y de Florencio del Castillo (2003). Sus más relevantes investigaciones son, sin duda, los libros Bartolomé de Las Casas ante la conquista de América. Las voces del historiador (1992), Entre la espada y el falo: la mujer americana bajo el conquistador europeo (1999) y La literatura iberoamericana del siglo XVIII (2005a), un ambicioso compendio que ofrece una visión de conjunto sobre esa centuria de transición de las formas y preocupaciones barrocas a las neoclásicas.

Con el siglo XXI, no ha dejado de crecer el número historiadores de la literatura que han volcado su atención sobre las letras coloniales. Ligia Bolaños Varela (2001, 2006a, 2006b y 2008) se ha enfocado, en lo esencial, en una reflexión teórica sobre la construcción del imaginario colonial mediante la escritura literaria, aunque también ha incursionado en un texto particular de Gonzalo Fernández de Oviedo (2003). El volumen colectivo El discurso colonial: construcción de una diferencia americana, editado por Albino Chacón ${ }^{19}$ y Catherine Poupeney Hart (2002), contiene dos estudios pertinentes: uno del propio Chacón sobre las posibilidades de la escritura en los inicios de la colonia en la región centroamericana y otro de Francisco Rodríguez sobre los ladinos en la Recordación florida de Fuentes y Guzmán.

Leonardo Sancho Dobles ha desplegado una intensa actividad alrededor de dos ejes fundamentales: la poesía de Sor Juana Inés de la Cruz (2006, 2009a, 2015a, 2015b, 2018a, 2018b, 2018c) y los entremeses de Joaquín de Oreamuno (2009b, 2011, 2013a, 2013b, 2013c), cuya edición crítica (2016) constituye la primera de un texto literario colonial costarricense ${ }^{20}$. Alexánder Sánchez Mora ha publicado, entre el 2016 y el 2020, doce artículos sobre las relaciones de fiestas centroamericanas, los cuales abarcan temas tan variados como la construcción del corpus (2016a, 2020), las proclamaciones eclesiásticas (2016 y 2018a), las exequias de reinas (2019b) y obispos (2018d), la consagración del templo de Esquipulas (2018c), el teatro colonial centroamericano (2019a) y las redes de poder del clan Pardo de Figueroa (2017a). Además, ha formulado una propuesta teórica para la ampliación del corpus literario colonial $(2019 \mathrm{c})^{21}$.

19 Chacón, junto con Magda Zavala (2008), es también autor de un estudio sobre las condiciones institucionales que incidieron en el desarrollo de la vida cultural en Centroamérica durante el periodo colonial.

20 El Dr. Sancho Dobles fue, además, el organizador del Congreso Internacional "La escritura en el desplazamiento: viajes, expediciones y naufragios", celebrado en San José y Golfito en octubre del 2019, el cual contó con una gran cantidad de participantes nacionales e internacionales.

21 Además, se encuentran en prensa artículos sobre la retórica de las relaciones de exequias fúnebres de los reyes y las justas poéticas mercedarias en honor a San Pedro Pascual de Valencia en Santiago de Guatemala (1673). 
Otros investigadores que han dedicado esfuerzos a la literatura colonial -y los tópicos que han tratado- durante los últimos años son los siguientes: Marlen Calvo Oviedo e Ivannia Barboza Leitón, la poesía religiosa centroamericana de los siglos XVI y XVII (2006); Ana Elena Castillo Víquez, el imaginario del paraíso en las cartas de Colón (2007); Gerardo Meza Sandoval, los villancicos de negros (2009); Jorge Chen, la naturaleza y la geografía en la Recordación Florida de Fuentes y Guzmán (2012) y el canibalismo en Pedro Cieza de León (2013 y 2018); Ronald Campos López, la relación intertextual entre el Diario de Colón y los textos de Américo Vespucio con los primeros mapas del continente (2014); Rima de Vallbona, la figura de la mujer azteca a partir de códices indígenas, crónicas y memoriales coloniales $(2015)^{22}$; Carlos Paniagua, la relación entre acontecimiento teatral y escritura dramática en el Rabinal Achí (2018); Deborah Singer, la construcción de la etnicidad en los villancicos de negros de la catedral de Santiago de Guatemala (2019), y Gustavo Camacho Guzmán, el teatro tardocolonial de Joaquín de Oreamuno y Víctor de la Guardia (2019)23.

El balance de este medio siglo de investigación, en especial de los últimos veinte años, es esperanzador: la cantidad y la variedad de los estudios no ha dejado de crecer. El incremento es especialmente palpable en la década reciente. Sin embargo, se ha continuado arrastrando una misma deficiencia: la práctica totalidad de estos esfuerzos, dignos de reconocimiento, son fruto de la iniciativa de académicos aislados y no de programas de investigación que habrían permitido dotarlos de continuidad y que habrían propiciado tanto el trabajo en equipo como la interdisciplinariedad. Otra debilidad detectada es la ausencia de una verdadera especialización: la mayoría de investigadores limita su producción colonialista a uno o dos artículos, lo cual atenta contra la profundidad y complejidad de los análisis e impide la consolidación de una tradición de estudios coloniales en el país. Uno de los mayores desafíos de los años venideros será el superar ese cierto diletantismo y promover la profesionalización de esta área de la historia literaria.

\subsection{Sexta tarea. La articulación institucional de la investigación}

En mayo del 2018, se efectuaron, bajo el auspicio del Instituto de Investigaciones Lingüísticas y la Escuela de Filología, Lingüística y Literatura de la Universidad de Costa Rica, las I Jornadas de Lengua y Literatura en la Colonia en Centroamérica: los discursos olvidados. Este primer encuentro convocó a veinticuatro ponentes, todos ellos docentes de la Escuela de Filología, Lingüística y Literatura, la Escuela de Historia y la Escuela de Estudios Generales de la Universidad de Costa Rica. Además, se contó con la presencia de tres investigadores de universidades extranjeras: el Dr. Dalmacio Rodríguez Hernández de la Universidad Nacional Autónoma de México, la Dra. Munia Cabal Jiménez de la Universidad de Western Illinois y el Dr. José Jaime García Bernal de la Universidad de Sevilla.

22 Rima de Vallbona es también autora del volumen De relatos y presagios. Relatos del pasado azteca (2011), el cual no incluimos en este recuento por tratarse de una obra de creación literaria.

23 Otros estudios coloniales de pronta aparición son: las memorias de las "I Jornadas de Lengua y Literatura en la Colonia en Centroamérica: los discursos olvidados”, que serán publicadas por la revista Káñina y que contienen artículos de Geaninni Ruiz Ulloa, Esteban López Arguedas, Maricela Cerdas Fallas, Sebastián Altamirano y Alexánder Sánchez; y el tomo VI, Textualidades indígenas y discursos y escrituras coloniales, del proyecto "Hacia una historia de las literaturas centroamericanas", editado por Ligia Bolaños Varela y Francisco Rodríguez Cascante. 
El éxito de tal encuentro académico impulsó de manera decidida el posicionamiento de los estudios coloniales centroamericanos como campo de interés para los especialistas en Lengua y Literatura. A lo largo de los años 2018 y 2019, se efectuó un buen número de conferencias, mesas redondas y talleres sobre temas tales como la edición de documentos lingüísticos de la Centroamérica colonial, las fuentes documentales del Archivo Histórico Arquidiocesano, los estudios genealógicos en Costa Rica, el estudio de la música colonial centroamericana y la edición de textos literarios ${ }^{24}$. Asimismo, se promovió la participación en talleres de paleografía y la visita a archivos. De manera paralela, se fomentó la inscripción de proyectos de investigación bajo el amparo del Instituto de Investigaciones Lingüísticas (INIL) y al momento presente se cuenta con los siguientes ya debidamente aprobados por la Vicerrectoría de Investigación de la Universidad de Costa Rica:

a) $\mathrm{N}^{\circ} \mathrm{B} 8 \mathrm{~A} 61$ "La fiesta barroca en la periferia. Relación de la fiesta de proclamación de Luis I en la ciudad de Cartago, Costa Rica (1725)" a cargo del Dr. Alexánder Sánchez Mora, investigador principal.

b) $\mathrm{N}^{\mathrm{o}} 363$ "Edición crítica de la Relación individual de las fiestas, con que se celebró la dedicación del suntuosísimo templo del Calvario de Esquipulas (1759) de Alonso de Arcos y Moreno", a cargo del Dr. Alexánder Sánchez Mora, investigador principal, y del Dr. Antonio Leoni de León, colaborador.

c) N ${ }^{\circ}$ C0094 “Constitución de un corpus histórico para el español colonial de Costa Rica. I Etapa” a cargo de la Dra. Gabriela Cruz Volio, investigadora principal.

d) No C0457 "Análisis lingüístico, literario e histórico del primer texto extenso en bribri y de su contexto de producción: el Evangelio según San Juan (1905) traducido por Guillermo Gabb”, a cargo del Dr. Carlos Sánchez Avendaño, investigador principal, y de la Dra. Verónica Ríos Quesada y la Dra. Alejandra Boza Villarreal, colaboradoras.

Sobre la base de estos proyectos será posible constituir, siempre dentro del marco del INIL, el Programa de Estudios Coloniales Centroamericanos, un espacio de reflexión académica sobre la lengua y la literatura que se abre a especialistas de otras áreas. Su propósito fundamental es propiciar un intercambio multidisciplinario que enriquezca el conocimiento sobre el periodo colonial de la región centroamericana.

Otro efecto positivo de las I Jornadas fue el visibilizar este campo de estudios ante la comunidad estudiantil. Como resultado de ello, ha aumentado el interés por realizar trabajos finales de graduación en esta área. Por el momento, hay dos tesis de maestría en curso: Teatro en la periferia. Representaciones del poder y de lo americano en los textos dramáticos de la relación "Plausibles fiestas reales" (1762) de Geaninni Ruiz Ulloa y El Peregrino

24 Para todas estas actividades se contó con la generosa colaboración de especialistas en las diversas áreas: el Dr. José Luis Ramírez Luengo de la Universidad Autónoma de Querétaro, la Dra. Gabriela Cruz Volio de la Escuela de Filología, Lingüística y Literatura de la Universidad de Costa Rica, la Dra. Deborah Singer González de la Escuela de Música de la Universidad Nacional, el M.L. Mauricio Meléndez Obando, presidente de la Academia Costarricense de Ciencias Genealógicas, el Dr. Eduardo Madrigal Muñoz de la Escuela de Historia de la Universidad de Costa Rica, el Dr. Leonardo Sancho de la Escuela de Estudios Generales de la Universidad de Costa Rica y el M. Sc. Pablo Durand Baquerizo, director del Archivo Histórico Arquidiocesano. 
Septentrional Atlante; hagiografía barroca y Propaganda Fide de Esteban López Arguedas, ambas bajo la dirección de Alexánder Sánchez Mora.

Finalmente, la celebración de las II Jornadas de Lengua y Literatura en Centroamérica en la colonia, programadas para celebrarse en setiembre del 2021, promete ser el espacio propicio para consolidar el incipiente desarrollo de los estudios coloniales, tanto linguísticos como literarios, en nuestra academia. Este encuentro permitirá a los investigadores poner en común sus avances y propuestas y, a la vez, nos desafía a definir un plan de abordaje conjunto para un universo tan poco conocido como el de la lengua y la literatura coloniales centroamericanas. El reto está planteado.

El recuento efectuado en las páginas antecedentes sobre la labor de la academia costarricense en el campo de las letras coloniales aspira a ser todo lo completo posible, pero no es exhaustivo; de manera involuntaria, se habrá dejado de lado el trabajo de algunos estudiosos del área. De igual modo, tampoco puede considerarse que las seis tareas propuestas constituyan la hoja de ruta única para lograr construir una sólida escuela de estudios coloniales centrados en la literatura centroamericana. Esta es solo una propuesta que, de forma necesaria, deberá verse enriquecida, complementada e, incluso, contrastada por los aportes que, en un diálogo abierto y constante, realice la comunidad de investigadores.

\section{Bibliografía}

Acosta Rodríguez, A. (2012). La moneda en El Salvador hacia 1850. En M. S. Elvás Iniesta y S. Olivero Guidobono (Eds.), Redescubriendo el Nuevo Mundo. Estudios americanistas en homenaje a Carmen Gómez (pp. 307-325). Sevilla: Secretariado de publicaciones de la Universidad de Sevilla.

Acuña Ortega, V. H. (1985-1986). La renovación de los estudios históricos en Costa Rica. Revista de Historia, 12-13, 11-16.

Bakewell, P. J. (1976). Minería y sociedad en el México colonial. Zacatecas (1546-1700). México: Fondo de Cultura Económica.

Barrantes, A. C. (1997). Buscando las raíces del modernismo en Costa Rica: cinco acercamientos. Heredia: EUNA.

Belaubre, C. (2016). Los sermones en el reino de Guatemala: un objeto para la historia social y política. Diálogos. Revista Electrónica de Historia, 17(especial), 85-124.

Blanco Segura, R. (1997). Entre pícaros y bobos. Crónicas. San José: EUNED.

Blanco Segura, R. (1983). Historia Eclesiástica de Costa Rica. Del Descubrimiento a la Erección de la Diócesis (1502-1850). San José: EUNED.

Bonilla, A. (1981). Historia de la literatura costarricense. San José: STUDIVM.

Borge, C. y Castillo, R. (1997). Cultura y conservación en la Talamanca indígena. San José: EUNED.

Botey, A. M. (1994). La República Federal (1823-1842). San José: Editorial de la Universidad de Costa Rica.

Brenes Castillo, M. E. (1978). Matina, bastión del contrabando en Costa Rica. Anuario de Estudios Centroamericanos, 4, 393-450. 
Bolaños Varela, L. (2001). Construcción del imaginario colonial y las escrituras fundacionales: mecanismos de diseminación/circulación del texto eclesiástico. Reflexiones, 80(1), 83-98.

Bolaños Varela, L. (2003). Una lectura de "Particular y sumaria relación de las materias que se han de tractar y escribir en cada uno, ó a lo menos de lo más substancial" del primer y segundo proemio del libro General y natural historia de las Indias, islas y tierrafirme del mar Océano de Gonzalo Fernández de Oviedo. Intercambios. Cuadernos de Centroamérica y el Caribe, 2. Recuperado de http://ciicla.ucr.ac.cr/sites/default/ files/2017-06/revista\%20cuadernos\%202.pdf

Bolaños Varela, L. (2006a). Colonialidad tardía y/o inicios del proceso republicano. Elementos para la constitución del campo literario en Centroamérica. Istmo, 12. Recuperado de http://istmo.denison.edu/n12/articulos/colonialidad.html

Bolaños Varela, L. (2006b). Escrituras fundacionales y procesos de desterritorialización en la colonia centroamericana. Istmo, 13. Recuperado de http://istmo.denison.edu/n13/ proyectos/escrituras.html

Bolaños Varela, L. (2008). Narraciones y temporalidades en la producción colonial centroamericana. W. Mackenbach (Ed.), Hacia una Historia de las Literaturas Centroamericanas" Intersecciones y transgresiones. Propuestas para una historiografía literaria en Centroamérica (Tomo I, pp. 151-170). Guatemala: F\&G Editores.

Calvo, Y. (1987). Dos escritoras barrocas: reflexión sobre la escritura femenina. Letras, 15-1617, 281-291.

Calvo Oviedo, M. y Barboza Leitón, I. (2006). Acercamiento a la poesía religiosa de la etapa colonial centroamericana siglos XVI y XVII desde: Sor Juana de Maldonado y Paz, Baltazar de Orena y Eugenio Salazar de Alarcón. Káñina, 30(1), 33-42.

Campos López, R. (2014). Los nuevos retratos de América: El Diario de navegación de Cristóbal Colón y las cartas de viajes y documentos de Américo Vespucio como intertextos de los primeros mapas americanos. Artifara, 14, 5-39.

Camacho Guzmán, G. (2019). El teatro centroamericano del ocaso colonial. Joaquín de Oreamuno y Víctor de la Guardia. Letras, 65, 13-37.

Castillo Víquez, A. E. (2007). Desde las Crónicas de Colón hasta nuestros días: el imaginario del paraíso en el Nuevo Mundo. Káñina, 31(2), 35-47.

Cardoso, C. F. y Pérez Brignoli, H. (1977). Centro América y la economía occidental (15201930). San José: Editorial de la Universidad de Costa Rica.

Castro Rawson, M. (1966). El costumbrismo en Costa Rica. San José: Editorial Costa Rica.

Chacón Hidalgo, M. B. (2005). Percepciones sociales e institucionales de la pobreza en Costa Rica colonial: siglos XVII y XVIII. En R. J. Viales Hurtado (Ed.), Pobreza e historia en Costa Rica: determinantes estructurales y representaciones sociales del siglo XVII a 1950 (pp. 173-191). San José: Editorial de la Universidad de Costa Rica.

Chacón Hidalgo, M. B. (2008). El cacao como moneda oficial en la Costa Rica del siglo XVIII. Numisma. Revista de Estudios Numismáticos, 252, 137-148. 
Chacón Hidalgo, M. B. (2014). Trueque y medios de cambio alternativos durante el período colonial en Costa Rica. En C. Velázquez Bonilla y E. Payne Iglesias (Coords.), Poder, economía y relaciones sociales en el Reino de Guatemala (pp. 71-87). San José: Editorial de la Universidad de Costa Rica.

Chacón, A. (2002). Posibilidades de escritura en los inicios de la colonia centroamericana. En A. Chacón y C. Poupeney Hart (Ed.), El discurso colonial: construcción de una diferencia americana (pp. 245-260). Heredia EUNA y Universidad de Montreal.

Chacón, A. y Zavala M. (2008). Instituciones y vida cultural en la colonia centroamericana. Telar. Revista del Instituto Interdisciplinario de Estudios Latinoamericanos, 5(6), 108-128.

Chase, A. (1975). Narrativa contemporánea de Costa Rica. (Tomo I). San José: Ministerio de Cultura, Juventud y Deportes.

Chen Sham, J. (2012). La bondadosa naturaleza y la geografía guatemalteca: el modelo fundacional de la Recordación Florida. Revista Iberoamericana, 78(251), 769-781.

Chen Sham, J. (2013). Las inscripciones corporales del indio: canibalismo y desnudez en Pedro Cieza de León. Revista de Filología y Lingüística, 39(1), 77-84.

Chen Sham, J. (2018). De 'lo crudo a lo cocido': variaciones sobre el canibalismo en Pedro de Cieza. Revista de Filología y Lingüística, 44(2), 27-35.

Cruz Volio, G. (2020). Comunicación personal. 29 de abril.

Díaz Arias, D. (2013). La construcción de las naciones centroamericanas, 1821-1954. En M. C. Mineiro Scatamacchia y F. Enríquez Solano (Eds.), América. La consolidación de las naciones (pp. 64-97). México: Instituto Panamericano de Geografía e Historia.

Dobles Yzaguirre, J. (1986). Las cartas de Juan Vázquez de Coronado. Praxis de una conquista. Letras, 11-12, 177-190.

Durán Luzio, J. (1991). A propósito de una nueva edición bilingüe de la Rusticatio mexicana, de Rafael Landívar. Revista Iberoamericana, 57(155-156), 591-596.

Durán Luzio, J. (1992). Bartolomé de Las Casas ante la conquista de América. Las voces del historiador. Heredia: EUNA. Segunda edición 2014.

Durán Luzio, J. (1999). Entre la espada y el falo: la mujer americana bajo el conquistador europeo. Heredia: EUNA.

Durán Luzio, J. (2003). Senderos de identidad. San José: Editorial Costa Rica.

Durán Luzio, J. (2005a). La literatura iberoamericana del siglo XVIII. Heredia: EUNA.

Durán Luzio, J. (2005b). Fray Bernardino de Sahagún: de coyotes, modo narrativo y los albores del llamado (mucho después) cuento hispanoamericano. Cuadernos americanos, 6(114), 25-36.

Fernández Guardia, R. (1975). Crónicas coloniales. San José: Editorial Costa Rica.

Fernández Molina, J. A. (2003). Pintando el mundo de azul. El auge añilero y el mercado centroamericano, 1750-1810. San Salvador: Concultura.

Fonseca Corrales, E., Alvarenga Venutolo, P. y Solórzano Fonseca, J. C. (2003). Costa Rica en el siglo XVIII. San José: Editorial de la Universidad de Costa Rica. 
González Villalobos, P. (1988). Los avatares de la 'nueva historia'. Revista de Historia, Número especial, 27-50.

Guevara, M. y Chacón, R. (1992). Territorios indios en Costa Rica: orígenes, situación actual y perspectivas. San José: Editorial García Hermanos.

Hall, C. y Pérez Brignoli, H. (2003). Historical Atlas of Central America. Norman: University of Oklahoma Press.

Hunt, N. (2013). Contraband, free ports, and British merchants in the Caribbean world, 17391772. Diacronie. Studi di Storia Contemporanea, 13, 1-12.

Láscaris Comneno, C. (1952). Fundamentación ideológica de Sor Juana Inés de la Cruz. Cuadernos Hispanoamericanos, 25, 50-62.

Láscaris Comneno, C. (1964). Historia de las ideas filosóficas en Costa Rica. San José: Editorial Costa Rica.

Láscaris Comneno, C. (1970). Historia de las ideas en Centroamérica. San José: Editorial Universitaria Centroamericana.

Lavallé, B. (2019). Los virreinatos de Nueva España y el Perú (1680-1740). Madrid: Casa de Velázquez.

Luján Muñoz, J. (1977). La independencia y la anexión de Centroamérica a México. Guatemala: Serviprensa Centroamericana.

MacLeod, M. J. (1973). Spanish Central America: a socioeconomic history, 1520-1720. Berkeley: University of California Press.

Madrigal Muñoz, E. (2011). Los lazos sociales en la dinámica de un grupo subordinado en una sociedad colonial periférica: los cacaoteros de Costa Rica. Mesoamérica, 53, 106-132.

Madrigal Muñoz, E. (2014). Otra mirada a las redes sociales coloniales: los cacaoteros de Cartago en el siglo XVII. En C. Velázquez Bonilla y E. Payne Iglesias (Coords.), Poder, economía y relaciones sociales en el Reino de Guatemala (pp. 103-112). San José: Editorial de la Universidad de Costa Rica.

Meléndez, C. (1984). Apuntes sobre el teatro culterano colonial en el reino de Guatemala. Revista del Pensamiento Centroamericano, 39(185), 82-89.

Meza Sandoval, G. E. (2009). Villancico de Negros, una ventana por donde se ve e integra al otro. Comunicación, 18(2), 13-21.

Miño Grijalva, M. (2001). El mundo novohispano. Población, ciudades y economía, siglos XVII y XVIII. México: Fondo de Cultura Económica.

Molina Montes de Oca, C. (2005). Y las mulas no durmieron: los arrieros en Costa Rica, siglos XVI al XIX. San José: EUNED.

Molina, I. y Palmer, S. (1997). Historia de Costa Rica: breve, actualizada y con ilustraciones. San José: Universidad de Costa Rica.

Montero Barrantes, F. (2003). Elementos de historia de Costa Rica 1502 - 1856. San José: EUNED. 
Mora, S. M. (1995). De la sujeción colonial a la patria criolla: El Periquillo sarniento y los orígenes de la novela en Hispanoamérica. Heredia: EUNA.

Obregón Loría, Rafael. (1977). Costa Rica en la Independencia y en la Federación. San José: Editorial Costa Rica.

Ovares, F., Rojas, M., Santander, C. y Carballo, M. E. (1993). La casa paterna. Escritura y nación en Costa Rica. San José: Editorial de la Universidad de Costa Rica.

Palmer, S. (1992). Sociedad anónima, cultura oficial. Inventando la nación en Costa Rica, 18481900. En I. Molina y S. Palmer (Eds.), Héroes al gusto y libros de moda. Sociedad y cambio cultural en Costa Rica (pp. 189-198). San José y South Woodstock, Vermont: Editorial Porvenir y Plumsock Mesoamerican Studies.

Palmer, S. (1995). Hacia la ‘autoinmigración'. El nacionalismo oficial en Costa Rica 18701930. En A. Taracena y J. Piel (Eds.), Identidades nacionales y Estado moderno en Centroamérica (pp. 75-85). San José: Editorial de la Universidad de Costa Rica.

Paniagua, C. (2018). Del acontecimiento teatral al papel: Rabinal Achí. Letras, 64, 87-107.

Pena Sueiro, N. (2005). Repertorio de Relaciones de Sucesos españolas en prosa impresas en pliegos sueltos en la Biblioteca Geral Universitaria de Coimbra (siglos XVI-XVIII). Madrid: Fundación Universitaria Española.

Peralta, H. G. (1968). Agustín de Iturbide y Costa Rica. San José: Editorial Costa Rica.

Quesada Camacho, J. R. (2003). Historia de la historiografía costarricense (1821-1940). San José: Editorial de la Universidad de Costa Rica.

Quesada, Á. (1986). La formación de la narrativa nacional costarricense 1890-1910. Enfoque histórico social. San José: Editorial de la Universidad de Costa Rica.

Quesada, Á. (1988). La voz desgarrada. La crisis del discurso oligárquico y la narrativa costarricense (1917-1919). San José: Editorial de la Universidad de Costa Rica.

Quesada, Á. (1999). Uno y los otros: identidad y literatura en Costa Rica 1890-1940. San José: Editorial de la Universidad de Costa Rica.

Quesada, Á. (2008). Breve historia de la literatura costarricense. San José: Editorial Costa Rica.

Quirós, C. (1996). La Era de la Encomienda. San José: Editorial de la Universidad de Costa Rica.

Robles Mohs, I. (1994a). Hernán Cortés y el intercambio textual. Káñina, 18(1), 239-246.

Robles Mohs, I. (1994b). Las Cartas de relación de Hernán Cortés: el entorno de producción, la intitulación y la circulación. Revista de Filología y Lingüística, 20(1), 7-23.

Robles Mohs, I. (1994c). Adán, el Edén y Abel o la estructura narrativa simbólica de las Cartas de relación de Hernán Cortés. Revista de Filología y Lingüística, 20(2), 31-45.

Rodríguez H., M. E. (1988). El Periquillo Sarniento: la novela latinoamericana en busca de su identidad. Revista de Filología y Lingüística, 14(1), 45-49. 
Rodríguez Moya, I. (2003). Iturbide: ¿Héroe o emperador? En M. Chust y V. Mínguez (Eds.), La construcción del héroe en España y México, 1789-1847 (pp. 211-229). Universitat de València.

Rodríguez Moya, I. (2006). El retrato en México: 1781-1867. Héroes, ciudadanos y emperadores para una nueva nación. Sevilla: Consejo Superior de Investigaciones Científicas, Diputación de Sevilla, Universidad de Sevilla.

Rojas, M. y Ovares, F. (1995a). 100 años de literatura costarricense. San José: Ediciones Farben.

Rojas, M. y Ovares, F. (1995b). En el tinglado de la eterna comedia. Teatro costarricense 1890-1950. Heredia: EUNA.

Rosés Alvarado, C. (1982). El ciclo del cacao en la economía colonial de Costa Rica, 16501794. Mesoamérica, 3(4), 247-277.

Ruz, M. H. (1991). Melodías para el tigre. Pablo de Rebullida y los indios de Talamanca. 16941709. Revista de Historia, 23, 59-105.

Sanabria Martínez, V. M. (1985). Historia de Nuestra Señora de los Ángeles. San José: Editorial Costa Rica.

Sánchez Mora, A. (2003). El Modernismo contra la Nación. La polémica literaria de 1894 en Costa Rica. Revista de Filología y Lingüística, 29(1), 103-117.

Sánchez Mora, A. (2007). Literatura e historia: La reconquista de Talamanca y los textos históricos de Ricardo Fernández Guardia. Revista de Filología y Lingüística de la Universidad de Costa Rica, 33(1), 61-78.

Sánchez Mora, A. (2016). La arquitectura efímera ilustrada: la elevación de un globo aerostático en el recibimiento del arzobispo Villegas (Guatemala, 1794). En I. Rodríguez Moya, M. de los Á. Fernández Valle, y C. López Calderón (Eds.), Arte y patrimonio en Iberoamérica. Tráficos transoceánicos (pp. 477-494). Castelló de la Plana: Publicacions de la Universitat Jaume I.

Sánchez Mora, A. (2017a). Redes familiares, prestigio y poder: el clan Pardo de Figueroa en las relaciones festivas guatemaltecas del siglo XVIII. En J. J. Iglesias Rodríguez y J. J. García Bernal (Eds.), Andalucía en el mundo atlántico moderno: agentes y escenarios (pp. 389-405). Madrid: Sílex ediciones S.L.

Sánchez Mora, A. (2017b). Guatemala por Fernando Séptimo: crisis dinástica, juegos de lealtad y afirmación del poder local en una relación de fiestas. Revista de Historia, 75, 159-188.

Sánchez Mora, A. (2018a). Las luces del cielo de la iglesia (1747) de Antonio de Paz y Salgado: la retórica del poder en la proclamación del arzobispado de Guatemala. Fronteras de la Historia, 23(1), 12-38.

Sánchez Mora, A. (2018b). Las fiestas de proclamación de Fernando VII en el reino de Guatemala: trasformación y supervivencia de un modelo retórico. Atenea, 517, 221-239.

Sánchez Mora, A. (2018c). Devoción y promoción personal en el reino de Guatemala: Relación individual de las fiestas con que se celebró la dedicación del suntuosísimo Templo del Calvario de Esquipulas (1759). Potestas. Estudios del Mundo Clásico e Historia del Arte, 13, 101-118. 
Sánchez Mora, A. (2018d). Las exequias episcopales en el antiguo reino de Guatemala: poder eclesiástico y clientelismo. Centroamericana, 28(2), 99-123.

Sánchez Mora, A. (2018e). El fasto de la continuidad dinástica en el antiguo reino de Guatemala: las proclamaciones y juras de Fernando VI a Carlos IV. Bibliographica americana. Revista interdisciplinaria de estudios coloniales, 14, 56-71.

Sánchez Mora, A. (2019a). El teatro en las fiestas de proclamación del antiguo reino de Guatemala. En M. Zugasti Zugasti y J. A. Cuñado Landa (Coords.), Teatro y Fiesta en el Siglo de Oro: ámbito hispánico (pp. 269-282). Toulousse: Presses Universitaires du Midi.

Sánchez Mora, A. (2019b). Las relaciones fúnebres de reinas del siglo XVIII en el antiguo reino de Guatemala: acercamiento a sus programas emblemáticos. En P. R. Cubillo y L. R. Campos (Eds.), Estudios actuales de literatura comparada: teorías de la literatura y diálogos interdisciplinarios (Vol. 2, pp. 295-315). San José: Vicerrectoría de Investigación, Universidad de Costa Rica.

Sánchez Mora, A. (2019c). La ampliación del corpus de la literatura colonial centroamericana: reflexiones teóricas. Revista de Filología y Lingüística de la Universidad de Costa Rica, 45(2), 101-113.

Sánchez Mora, A. (2020). Las relaciones de fiestas del reino de Guatemala (1663-1814): la construcción del corpus. Káñina. Revista de Artes y Letras de la Universidad de Costa Rica, 44(1), 71-98.

Sancho Dobles, L. (2006). Diversa de sí misma: Sor Juana Inés de la Cruz ante la crítica canónica. Káñina, 30(1), 43-55.

Sancho Dobles, L. (2009a). La voz otra en Sor Juana Inés de la Cruz. Las contradicciones entre la razón y la pasión. San José: Editorial de la Universidad de Costa Rica.

Sancho Dobles, L. (2009b). Unos jocosos entremeses de Joaquín de Oreamuno. Bicentenario de tres piezas dramáticas del patrimonio cultural y literario de la colonia costarricense. Revista Herencia, 22(1), 5-84.

Sancho Dobles, L. (2011). Siclaco verbum caro: ecos del teatro áureo en la provincia más distante de la Nueva España. En C. Parodi y J. Rodríguez (Eds.), Centro y periferia. Cultura, lengua y literatura virreinales en América (pp. 147-158). Madrid: Iberoamericana-Vervuert.

Sancho Dobles, L. (2013a). ...porque ninguna es perfecta si hemos de hablar por lo claro': un retrato de las mujeres en la literatura colonial costarricense. Revista de Filología y Lingüística de la Universidad de Costa Rica, 39(1), 47-59.

Sancho Dobles, L. (2013b). Siclaco, Serapio y Calandraco: una caracterización del teatro breve en la provincia de Costarrica. Vanderbilt e-Journal of Luso Hispanic Studies, 9, 159-169.

Sancho Dobles, L. (2013c). Festividad barroca e hibridez textual en la provincia de Costarrica. En C. Parodi, M. Pérez y J. Rodríguez (Eds.), La resignificación del Nuevo Mundo: crónica, retórica y semántica en la América virreinal (pp. 211-226). Madrid: Iberoamericana Editorial Verbuert.

Sancho Dobles, L. (2015a). "Halló Celia una vela en el tablado": de mujeres y criadas y otros 
detalles en la poética de Sor Juana Inés de la Cruz. En M. Donoso (Coord.), Mujer y literatura femenina en la América virreinal (pp. 177-189). Estados Unidos: Instituto de Estudios Auriseculares.

Sancho Dobles, L. (2015b). "Una flor al tiempo dedicada": la voz de Celia en la poética de Sor Juana Inés de la Cruz. Perífrasis, 12, 62-75.

Sancho Dobles, L. (2016). Teatro breve en la provincia de Costa Rica. Tres piezas de Joaquín de Oreamuno y Muñoz de la Trinidad. Nueva York: IDEA.

Sancho Dobles, L. (2018a). Hacia un estado de la cuestión: algunas minucias del teatro breve de Sor Juana Inés de la Cruz. eHumanista, 40, 36-41.

Sancho Dobles, L. (2018b). Del caos al cosmos en los jardines de la Virreina: ecos y espejos en la "Loa en las huertas" de Sor Juana Inés de la Cruz. Revista Estudios, Número extra, 33-40.

Sancho Dobles, L. (2018c). "Con vos de centellas y con grito de olores": variaciones de un tópico barroco en tres piezas de Sor Juana Inés de la Cruz. En I. Arellano Ayuso y R. A. Rice (Coords.), Barroco de ambos mundos. Miradas desde Puebla (pp. 299-318). Estados Unidos: Instituto de Estudios Auriseculares.

Segura Montero, A. (1995). La Polémica (1894-1902): el nacionalismo en literatura. San José: EUNED.

Serrera Contreras, R. (2013). La América de los Habsburgo (1517-1700). Sevilla: Secretariado de Publicaciones de la Universidad de Sevilla.

Singer, D. (2019). Inclusion Politics/Subalternization Practices: the construction of ethnicity in Villancicos de Negros of the Cathedral of Santiago de Guatemala (16th-18th centuries). Revista de Historia, 80, 33-53.

Solórzano Fonseca, J. C. (1994). El comercio de Costa Rica durante el declive del comercio español y el desarrollo del contrabando inglés, período 1690-1750. Anuario de Estudios Centroamericanos, 20(2), 70-120.

Solórzano, J. C. (1992). Conquista, colonización y resistencia indígena en Costa Rica. Revista de Historia, 25, 191-205.

Sotela, R. (1938). Literatura costarricense. San José: Lehmann.

Toussaint, M., Rodríguez de Ita, G. y Vásquez Olivera, M. (2001). Vecindad y diplomacia: Centroamérica en la política exterior mexicana, 1821-1983. México: Secretaría de Relaciones Exteriores.

Townsend Ezcurra, A. (1973). Las Provincias Unidas de Centroamérica: fundación de la república. San José: Editorial Costa Rica.

Umaña Chaverri, J. O. (1992). Interpretación y traducción de América en el Diario de navegación de Cristóbal Colón. Letras, 25-26, 107-120.

Vallbona, R. de. (1993). Vida i Sucesos de la Monja Alférez: autobiografía atribuida a Doña Catalina de Erauso. Tempe, Arizona: Center for Latin American Studies. 
Vallbona, R. de. (1995). Los conventos coloniales como espacios liberadores y de creación para la mujer. Revista de Filología y Lingüística, 1(extraordinario), 7-23.

Vallbona, R. de. (2000). La décima musa de Nueva España, Sor Juana Inés de la Cruz, y la Nueva Inglaterra, Anne Bradstret: represión patriarcal religiosa y socio-cultural durante la colonia. En J. Chen Sham (Ed.), VII Congreso Costarricense de Filología, Lingüística y Literatura Dr. Jack Wilson Kilburn, 22, 23 y 24 de octubre de 1997 (pp. 81-99). San José: Oficina de Publicaciones de la Universidad de Costa Rica.

Vallbona, R. de. (2015). Voces olvidadas de la mujer azteca. Su rescate en códices indígenas, crónicas y memoriales coloniales. EE.UU: Academia Norteamericana de la Lengua.

Valdeperas, J. (1991). Para una nueva interpretación de la literatura costarricense. San José: Editorial Costa Rica.

Vargas Araya, A. (2006). El Doctor Zambrana: padre y maestro de la democracia republicana costarricense. San José: EUNED.

Vázquez Olivera, M. (2004). El Plan de Iguala y la independencia guatemalteca. En A. C. Ibarra (Coord.), La independencia en el Sur de México (pp. 395-430). México: UNAM.

Vázquez Olivera, M. (2010). El Imperio Mexicano y el Reino de Guatemala. Proyecto político y campaña militar, 1821-1823. México: Fondo de Cultura Económica.

Vázquez Vicente, G. (2011). Nacimiento y ocaso de la Federación de Centro América: entre la realidad y el deseo. Revista Complutense de Historia de América, 37, 253-275.

Villalobos, C. M. (2005). Partidas epistémicas de los estudios crítico-literarios en Costa Rica. Revista de Filología y Lingüística, 31(extraordinario), 131-145.

Wortman,M.(1976).Legitimidad política y regionalismo.El imperio mexicano y Centroamérica. Historia mexicana, 26(2), 238-262.

Zavala, M., Araya, S. y Chacón, A. (1995). La historiografía literaria en América Central (1957-1987). Heredia: EUNA.

\section{Anexo.}

\section{Bibliografía provisional de los estudios costarricenses sobre literatura colonial}

Bolaños Varela, L. (1992). Una nueva visión de la conquista. Herencia, 4(1-2), 63-69.

Bolaños Varela, L. (2001). Construcción del imaginario colonial y las escrituras fundacionales: mecanismos de diseminación/circulación del texto eclesiástico. Reflexiones, 80(1), $83-98^{25}$.

Bolaños Varela, L. (2003). Una lectura de "Particular y sumaria relación de las materias que se han de tractar y escribir en cada uno, ó a lo menos de lo más substancial” del primer y segundo proemio del libro General y natural historia de las Indias, islas y tierrafirme del mar Océano de Gonzalo Fernández de Oviedo. Intercambios. Cuadernos

25 También se publicó en Chacón, A. y Poupeney Hart, C. (2002). El discurso colonial: construcción de una diferencia americana. Heredia EUNA y Universidad de Montreal. 
de Centroamérica y el Caribe, 2. Recuperado de: http://ciicla.ucr.ac.cr/sites/default/ files/2017-06/revista\%20cuadernos\%202.pdf

Bolaños Varela, L. (2006a). Colonialidad tardía y/o inicios del proceso republicano. Elementos para la constitución del campo literario en Centroamérica. Istmo, 12. Recuperado de: http://istmo.denison.edu/n12/articulos/colonialidad.html

Bolaños Varela, L. (2006b). Escrituras fundacionales y procesos de desterritorialización en la colonia centroamericana. Istmo, 13. Recuperado de: http://istmo.denison.edu/n13/ proyectos/escrituras.html

Bolaños Varela, L. (2008). Narraciones y temporalidades en la producción colonial centroamericana. W. Mackenbach, (ed.), Hacia una Historia de las Literaturas Centroamericanas" Intersecciones y transgresiones. Propuestas para una historiografía literaria en Centroamérica (Tomo I, pp. 151-170). Guatemala: F\&G Editores.

Calvo Oviedo, M. y Barboza Leitón, I. (2006). Acercamiento a la poesía religiosa de la etapa colonial centroamericana siglos XVI y XVII desde: Sor Juana de Maldonado y Paz, Baltazar de Orena y Eugenio Salazar de Alarcón. Káñina, 30(1), 33-42.

Calvo, Y. (1987). Dos escritoras barrocas: reflexión sobre la escritura femenina. Letras, 15-1617, 281-291.

Camacho Guzmán, G. (2019). El teatro centroamericano del ocaso colonial. Joaquín de Oreamuno y Víctor de la Guardia. Letras, 65, 13-37.

Campos López, R. (2014). Los nuevos retratos de América: El Diario de navegación de Cristóbal Colón y las cartas de viajes y documentos de Américo Vespucio como intertextos de los primeros mapas americanos. Artifara, 14, 5-39.

Castillo Víquez, A. E. (2007). Desde las Crónicas de Colón hasta nuestros días: el imaginario del paraíso en el Nuevo Mundo. Káñina, 31(2), 35-47.

Chacón, A. (2002). Posibilidades de escritura en los inicios de la colonia centroamericana. En A. Chacón y C. Poupeney Hart (ed.), El discurso colonial: construcción de una diferencia americana (pp. 245-260). Heredia EUNA y Universidad de Montreal.

Chen Sham, J. (2012). La bondadosa naturaleza y la geografía guatemalteca: el modelo fundacional de la Recordación Florida. Revista Iberoamericana, 78(251), 769-781.

Chen Sham, J. (2013). Las inscripciones corporales del indio: canibalismo y desnudez en Pedro Cieza de León. Revista de Filología y Lingüística, 39(1), 77-84.

Chen Sham, J. (2018). De 'lo crudo a lo cocido': variaciones sobre el canibalismo en Pedro de Cieza. Revista de Filología y Lingüística, 44(2), 27-35.

Dobles Yzaguirre, J. (1986). Las cartas de Juan Vázquez de Coronado. Praxis de una conquista. Letras, 11-12, 177-190.

Durán Luzio, J. (1979). Nuevo Mundo y realidad, realidad y fantasía. En Creación y Utopía: Letras de Hispanoamérica (pp. 11-21). Heredia: EUNA.

Durán Luzio, J. (1992a). Crónicas marcianas: de la conquista de América a la conquista de Marte. Letras, 25-26, 83-106. 
Durán Luzio, J. (1992b). Bartolomé de Las Casas ante la conquista de América. Las voces del historiador. Heredia: EUNA. Segunda edición 2014.

Durán Luzio, J. (1994). Bartolomé de las Casas ante la conquista de América. Revista chilena de literatura, 44, 160-163.

Durán Luzio, J. (1997). Jovellanos y Goicoechea; de cómo combatir la pobreza. VI Congreso de Filología, Lingüística y Literatura. Universidad Nacional, Heredia.

Durán Luzio, J. (1999). Entre la espada y el falo: la mujer americana bajo el conquistador europeo. Heredia: EUNA.

Durán Luzio, J. (2000). Florencio del Castillo, precursor de los derechos de propiedad intelectual en Hispanoamérica. VII Congreso Costarricense de Filología, Lingüística y Literatura. Universidad de Costa Rica.

Durán Luzio, J. (2003). Senderos de identidad. San José: Editorial Costa Rica.

Durán Luzio, J. (2005a). La literatura iberoamericana del siglo XVIII. Heredia: EUNA.

Durán Luzio, J. (2005b). Fray Bernardino de Sahagún: de coyotes, modo narrativo y los albores del llamado (mucho después) cuento hispanoamericano. Cuadernos americanos, 6(114), 25-36.

Durán Luzio, J. (1991). A propósito de una nueva edición bilingüe de la Rusticatio mexicana, de Rafael Landívar. Revista Iberoamericana, 57(155-156), 591-596.

Láscaris Comneno, C. (1952). Fundamentación ideológica de Sor Juana Inés de la Cruz. Cuadernos Hispanoamericanos, 25, 50-62.

Meléndez, C. (1984). Apuntes sobre el teatro culterano colonial en el reino de Guatemala. Revista del Pensamiento Centroamericano, 39(185), 82-89.

Meza Sandoval, G. E. (2009). Villancico de Negros, una ventana por donde se ve e integra al otro. Comunicación, 18(2), 13-21.

Mora, S. M. (1983). Para una lectura de El Periquillo Sarniento de Lizardi. Letras, 5-6, 73-116.

Mora, S. M. (1995). De la sujeción colonial a la patria criolla: El Periquillo sarniento y los orígenes de la novela en Hispanoamérica. Heredia: EUNA.

Paniagua, C. (2018). Del acontecimiento teatral al papel: Rabinal Achí. Letras, 64, 87-107.

Robles Mohs, I. (1994a). Hernán Cortés y el intercambio textual. Káñina, 18(1), 239-246.

Robles Mohs, I. (1994b). Las Cartas de relación de Hernán Cortés: el entorno de producción, la intitulación y la circulación. Revista de Filología y Lingüística, 20(1), 7-23.

Robles Mohs, I. (1994c). Adán, el Edén y Abel o la estructura narrativa simbólica de las Cartas de relación de Hernán Cortés. Revista de Filología y Lingüística, 20(2), 31-45.

Rodríguez H., M. E. (1988). El Periquillo Sarniento: la novela latinoamericana en busca de su identidad. Revista de Filología y Lingüística, 14(1), 45-49.

Rodríguez, F. (2002). Los otros ladinos en la Recordación florida de Fuentes y Guzmán. En A. Chacón y C. Poupeney Hart (eds.), El discurso colonial: construcción de una diferencia americana (pp. 289-308). Heredia EUNA y Universidad de Montreal. 
Sánchez Mora, A. (2016a). Las relaciones de fiestas en el Reino de Guatemala, siglos XVII a XIX. Anales de la Academia de Geografía e Historia de Guatemala, 91, 115-146.

Sánchez Mora, A. (2016b). La arquitectura efímera ilustrada: la elevación de un globo aerostático en el recibimiento del arzobispo Villegas (Guatemala, 1794). En I. Rodríguez Moya, M. de los Á. Fernández Valle, y C. López Calderón, (eds.), Arte y patrimonio en Iberoamérica. Tráficos transoceánicos (pp. 477-494). Castelló de la Plana: Publicacions de la Universitat Jaume I.

Sánchez Mora, A. (2017a). Redes familiares, prestigio y poder: el clan Pardo de Figueroa en las relaciones festivas guatemaltecas del siglo XVIII. En J. J. Iglesias Rodríguez y J. J. García Bernal (eds.), Andalucía en el mundo atlántico moderno: agentes y escenarios (pp. 389-405). Madrid: Sílex ediciones S.L.

Sánchez Mora, A. (2017b). Guatemala por Fernando Séptimo: crisis dinástica, juegos de lealtad y afirmación del poder local en una relación de fiestas. Revista de Historia, 75, 159-188.

Sánchez Mora, A. (2018a). Las luces del cielo de la iglesia (1747) de Antonio de Paz y Salgado: la retórica del poder en la proclamación del arzobispado de Guatemala. Fronteras de la Historia, 23(1), 12-38.

Sánchez Mora, A. (2018b). Las fiestas de proclamación de Fernando VII en el reino de Guatemala: trasformación y supervivencia de un modelo retórico. Atenea, 517, 221239.

Sánchez Mora, A. (2018c). Devoción y promoción personal en el reino de Guatemala: Relación individual de las fiestas con que se celebró la dedicación del suntuosísimo Templo del Calvario de Esquipulas (1759). Potestas. Estudios del Mundo Clásico e Historia del Arte, 13, 101-118.

Sánchez Mora, A. (2018d). Las exequias episcopales en el antiguo reino de Guatemala: poder eclesiástico y clientelismo. Centroamericana, 28(2), 99-123.

Sánchez Mora, A. (2018e). El fasto de la continuidad dinástica en el antiguo reino de Guatemala: las proclamaciones y juras de Fernando VI a Carlos IV. Bibliographica americana. Revista interdisciplinaria de estudios coloniales, 14, 56-71.

Sánchez Mora, A. (2019a). El teatro en las fiestas de proclamación del antiguo reino de Guatemala. En M. Zugasti Zugasti y J. A. Cuñado Landa (coords.), Teatro y Fiesta en el Siglo de Oro: ámbito hispánico (pp. 269-282). Toulousse: Presses Universitaires du Midi.

Sánchez Mora, A. (2019b). Las relaciones fúnebres de reinas del siglo XVIII en el antiguo reino de Guatemala: acercamiento a sus programas emblemáticos. En P. R. Cubillo y L. R. Campos (eds.), Estudios actuales de literatura comparada: teorías de la literatura y diálogos interdisciplinarios (Vol. 2, pp. 295-315). San José: Vicerrectoría de Investigación, Universidad de Costa Rica.

Sánchez Mora, A. (2019c). La ampliación del corpus de la literatura colonial centroamericana: reflexiones teóricas. Revista de Filología y Lingüística de la Universidad de Costa Rica, 45(2), 101-113. 
Sancho Dobles, L. (2006). Diversa de sí misma: Sor Juana Inés de la Cruz ante la crítica canónica. Káñina, 30(1), 43-55.

Sancho Dobles, L. (2008). El patrimonio literario de los archivos (hacia un bosquejo de la literatura colonial en Costa Rica). Herencia, 21(2), 7-16.

Sancho Dobles, L. (2009a). La voz otra en Sor Juana Inés de la Cruz. Las contradicciones entre la razón y la pasión. San José: Editorial de la Universidad de Costa Rica.

Sancho Dobles, L. (2009b). Unos jocosos entremeses de Joaquín de Oreamuno. Bicentenario de tres piezas dramáticas del patrimonio cultural y literario de la colonia costarricense. Revista Herencia, 22(1), 5-84.

Sancho Dobles, L. (2011). Siclaco verbum caro: ecos del teatro áureo en la provincia más distante de la Nueva España. En C. Parodi y J. Rodríguez (eds.), Centro y periferia. Cultura, lengua y literatura virreinales en América (pp. 147-158). Madrid: Iberoamericana-Vervuert.

Sancho Dobles, L. (2012). Así como arde este fuego: la provincia de Costarrica se deslumbra en enero de 1809. Comunicación, 21(1), 25-32.

Sancho Dobles, L. (2013a). ...'porque ninguna es perfecta si hemos de hablar por lo claro': un retrato de las mujeres en la literatura colonial costarricense. Revista de Filología y Lingüística de la Universidad de Costa Rica, 39(1), 47-59.

Sancho Dobles, L. (2013b). Siclaco, Serapio y Calandraco: una caracterización del teatro breve en la provincia de Costarrica. Vanderbilt e-Journal of Luso Hispanic Studies, 9, 159169.

Sancho Dobles, L. (2013c). Festividad barroca e hibridez textual en la provincia de Costarrica. En C. Parodi, M. Pérez y J. Rodríguez (eds.), La resignificación del Nuevo Mundo: crónica, retórica y semántica en la América virreinal (pp. 211-226). Madrid: Iberoamericana Editorial Verbuert.

Sancho Dobles, L. (2015a). "Halló Celia una vela en el tablado": de mujeres y criadas y otros detalles en la poética de Sor Juana Inés de la Cruz. En M. Donoso (coord.), Mujer y literatura femenina en la América virreinal (pp. 177-189). Estados Unidos: Instituto de Estudios Auriseculares.

Sancho Dobles, L. (2015b). "Una flor al tiempo dedicada": la voz de Celia en la poética de Sor Juana Inés de la Cruz. Perífrasis, 12, 62-75.

Sancho Dobles, L. (2016). Teatro breve en la provincia de Costa Rica. Tres piezas de Joaquín de Oreamuno y Muñoz de la Trinidad. Nueva York: IDEA.

Sancho Dobles, L. (2018a). Hacia un estado de la cuestión: algunas minucias del teatro breve de Sor Juana Inés de la Cruz. eHumanista, 40, 36-41.

Sancho Dobles, L. (2018b). Del caos al cosmos en los jardines de la Virreina: ecos y espejos en la "Loa en las huertas" de Sor Juana Inés de la Cruz. Revista Estudios, Número extra, 33-40.

Sancho Dobles, L. (2018c). “Con vos de centellas y con grito de olores": variaciones de un tópico barroco en tres piezas de Sor Juana Inés de la Cruz. En I. Arellano Ayuso y R. 
A. Rice (coords.), Barroco de ambos mundos. Miradas desde Puebla (pp. 299-318). Estados Unidos: Instituto de Estudios Auriseculares.

Singer, D. (2019). Inclusion Politics/Subalternization Practices: the construction of ethnicity in Villancicos de Negros of the Cathedral of Santiago de Guatemala (16th-18th centuries). Revista de Historia, 80, 33-53.

Umaña Chaverri, J. O. (1992). Interpretación y traducción de América en el Diario de navegación de Cristóbal Colón. Letras, 25-26, 107-120.

Vallbona, R. de. (1993). Vida i Sucesos de la Monja Alférez: autobiografía atribuida a Doña Catalina de Erauso. Tempe, Arizona: Center for Latin American Studies.

Vallbona, R. de. (1995). Los conventos coloniales como espacios liberadores y de creación para la mujer. Revista de Filología y Lingüística, 1(extraordinario), 7-23.

Vallbona, R. de. (2000). La décima musa de Nueva España, Sor Juana Inés de la Cruz, y la Nueva Inglaterra, Anne Bradstret: represión patriarcal religiosa y socio-cultural durante la colonia. En J. Chen Sham (ed.), VII Congreso Costarricense de Filología, Lingüística y Literatura Dr. Jack Wilson Kilburn, 22, 23 y 24 de octubre de 1997 (pp. 81-99). San José: Oficina de Publicaciones de la Universidad de Costa Rica.

Vallbona, R. de. (2015). Voces olvidadas de la mujer azteca. Su rescate en códices indígenas, crónicas y memoriales coloniales. EE.UU: Academia Norteamericana de la Lengua. 